\title{
Science Communication Activities Based on the Energy and Environmental Education in the Kansai Photon Science Institute and the Kids' Science Museum of Photons
}

\author{
Taiji Hoshiya ${ }^{1}$, Akihiko Nishimura ${ }^{2}$, Masahiro Nisikawa ${ }^{3}$ \\ Kansai Photon Science Institute, Japan Atomic Energy Agency ${ }^{1}$ \\ Quantum Beam Science Directorate, Japan Atomic Energy Agency ${ }^{2}$ \\ Graduate School of Engineering, Osaka University ${ }^{3}$
}

\begin{abstract}
"The Kids' Science Museum of Photons (KSMP)", which is attached to the Kansai Photon Science Institute (KPSI) of the Japan Atomic Energy Agency (JAEA) and is managed as an unique and experienced study type of museum with the theme of the photon science inside and outside of country, provides us with the mystery of light through various exhibits, theater, and experimental events and develops "Heart of Science". In this museum, various kinds of activities; experiments and/or work schools, coordinated course, the science festival, inservice training of teachers, are associated with regional administrative offices, educational institutions, and schools, and some of activities can be supported by the KPSI. In this research, the outline of science communication activities of energy and environmental education such as recent coordinated course, the experiment booth village and the science-walker, which has been extensively carried out by the KPSI and the KSMP, while sharing a role, is discussed in the degree of understanding, inquiring mind and its effects.
\end{abstract}

\section{Introduction}

The Kansai Photon Science Institute (KPSI) of the Japan Atomic Energy Agency (JAEA) was established for the purpose of the R\&D in the field of photon science. Major mission is to develop new type of high power and ultra short pulse laser source and its application, from the viewpoint of the quantum beam science including radiation beam.

The Kids' Science Museum of Photons (KSMP), which is attached to the KPSI of JAEA, is managed as an unique and experienced study type of museum with the theme of the photon science inside and outside of country, provides us with the mystery of light through various exhibits, theater, and experimental events and develops "Heart of Science”.
In this paper, the outline of science communication activities based on energy and environmental education in the KPSI and the KSMP are also described on the understanding for science and technology which are associated with local administrative offices, educational institutions, schools and public people. The purpose of this study is to clarify the outline of promoting activities on understanding for science and technology in the KPSI and the KSMP.

\section{Development of promoting activities for science and technology}

Promotion activity on understanding of science and technology is mainly imposed on a role as the key interface between a research and general society [1]. The KPSI and KSMP have shared a role on promoting activities of science and technology understanding. The former has performed the science seminar (S-cube), the science camp for high school students and the science lecture meeting for public people. On the other hand, the latter has complimentarily held the cooperation lecture, the lecture school, the science club, experiments and workshops for infant, grade-schooler and junior high school student.

\subsection{Administrative offices}

Cooperative and joint events have been held every year as the science festival for these six years. The purpose of the local administrative offices is mainly to make a city planning. Another purpose is also to have a pleasant experience for general people through events such as experiments and workshops holding.

\subsection{Educational institution}

In-service training seminars for teachers have been held for six years. It targets teachers for the 
elementary school and/or the junior high school. Various kinds of seminars have been planned, from the viewpoint of course of study, principle, experimental procedure and the degree of understanding. In this paper, seminars have been carried out and been classified into four type of category by its features.

\subsection{Schools}

Dispatch lectures from the KPSI and the KSMP, experiments and workshops courses have often been performed, cooperated with local primary schools, junior high schools in Kizugawa city, and/or high school in Kyoto prefecture, and Yamashiro-area, south half part of Kyoto prefecture, Japan.

\subsection{Pubic peoples}

Science lecture and science-café for public people including local primary school students, have been planned with the theme of energy and environments. The purpose of these events is mainly to create the mutual understanding between the sender (research institutes, science museums and universities) and the receiver (public people) on the information. Table 1 shows the outline of curriculums on "Wonder of the light" in the field of photon science for younger students.

\section{Results}

Some of unique events, which seem to be effective to improve the level of mutual information exchange between the lecturer and participants, are introduced for the development of the understanding the science and technology.

\subsection{Science festival}

We get approximately 7,000 visitors in these six years and it is shown that the outline of these science festivals is gradually infiltrating into Yamashiro area, south part of Kyoto prefecture, Japan. In addition, it is with extent and an action with the depth by cooperation and the cooperation with the local administration (Yamashiro-wide area development and promotion bureau), educational institution (Yamashiro-educational bureau) for the continuation holding more while reviewing contents in every year such as a food tasting corner "Marukajiri Festa", a corporate exhibition-booth and a science-rally, etc.

\subsection{In-service training seminar for teachers}

In cooperation with the local board of education, training seminars for teachers have been carried out about approximately 600 people, in these six years.
The content of in-service training seminar is composed of four type of one for teachers. (1) Outreach activity type that combines the introduction of a state-of-the-art research and (2) Practice experienced type (practice of the experiment) and (3) Development type of teaching materials and experiments applicable to the school lecture and (4) Edutainment type to experience the happiness as shown in Table 2.

(1) The outreach activity type of training is useful for the presentation of new knowledge and the information, although it was evaluated to be slightly a low value on the motivation and the prototypical experience effect of this type which has been mainly supported by the public acceptance (PA) activity of the research institute. The interests in the science and the technology have furthermore increased to the participant who already has abundant knowledge and the motivation by means of presenting and introducing a new methodology.

(2) "Practice experience type" is thought to be an improved version of the outreach activity type. The evaluated value on the content was highly increased after reducing the degree of PA activity. From the viewpoint of getting the new knowledge, it was expected that the including ratio of the up-to-date contents tends to decrease, although the normal contents were examined enough. It is, therefore, future problem whether they can be obtained as a key content and easily applied to the school spot or not.

(3) As for "Development type of teaching materials and experiments applicable to school lecture", it has generally obtained good value to be estimated. The effect of a practice experience depends on the completeness in developing teaching materials, learning effects by using these materials, the applicability to the school site, and the difficulty in how to present as a lecturer. It is important for us to develop an excellent learning material, and build up and open the systematic information database, and also to share the common issues to be solved inservice training of teachers [2].

(4) In "Edutainment type to experience the happiness", both the research institute and the science museum are also considered as the common place which participants can easily enjoy the science and technology. The lecturer staffs can closely talk with participants by using the experiment-booth and decide to satisfy the demands of participants. As this result, the high values to be evaluated were obtained in respect of the motivation, the effect of a practice experience, and fresh discoveries. This reveals the possibility of the local science museum to act as a key place to be associated with several kinds of issues at school spot; the pointed out matter on the importance of "studying while enjoying it", and how to show the knowhow as a lecturer and the methodology. 


\subsection{Cooperation lecture}

Cooperation and the dispatch lectures of the Science Partnership Project (SPP), supported by the Japan Science and Technology Agency (JST), that makes the researcher of the JAEA and other research institute, the museum attendant and the professor of the university as visiting lecturers, have been performed for the high school and the junior high school.

Table 3 shows the example of a coordinated lecture concerning the energy and environment with the high school for the second grader in the Yamashiro-area, Kyoto prefecture, in 2009 fiscal year. Neither understanding level nor its effect were enough in the lecture course, since the sufficient time could not be provided to experience the experiments due to the short curriculum. It has, however, been shown that the effect to exceed the experience-based experiments was obtained by the lecture experiments without experience-based experiments, if the contents of lecture, experiments and how to present the experiments are fully examined. It is interesting by the lecture on an up-to-date research on the selfregenerative type of catalyst using the synchrotron radiation (the Super Photon ring - 8GeV (SPring-8) ) that the significant effect more than experiencebased experiments is provided by the lecturer experiment without experience-based experiments.

As for a reference, Table 4 shows another example of a coordinated lecture concerning the energy of light with students of the primary school for same area.

\subsection{Science-walker}

The most effective and innovative trial events are called as the science-walker among the delivery and dispatch lectures. The delivery experiment lectures with the theme of photon science and energy were performed in the cooperation with the Yamashiroeducation bureau and others in 2008 fiscal year, because of each theme of (1)"Touched off", (2)"Search", (3)"Flashed", and (4)"Opened up", and the 595 junior high school students participation were obtained. Table 5 shows the summary of the results of questionnaire, and furthermore, changes in the degree of motivation in the field of the science were easily obtained in these lectures.

(1)"Touched off" (road to the expert on experiments). It aims at generation and the deepening of the interest and the concern in each field through the experience of mysterious phenomena.

(2)"Search" (seeing is believing). The optical microscope, the electron microscope, atomic force microscope, and the telescope, which include the experimental techniques that made an epoch in science history, were introduced and experienced by participants.

(3)"Flashed" (Scientist / to trace the Nobel Prize winning experiment).

(4)"Opened up" (mapping science / to obtain the whole image of experiments).

Table 5 shows the result of the questionnaire. An affirmative answer is obtained about the participant of about 70 to 90 percent. In each course "Touched off" (the 1st), "Search" (the 2nd), and "Flashed" (the 3rd) revealed 80 percent as for interesting level, and over 90 percent as for the understanding level. On the other hand, it has decreased to about 60 percent in the 4th course "Opened up". It is expected that the understanding level was not enough necessarily because difficulty level was higher than that of conventional theme in order to make the map about light, energy, space and the environment and to obtain the whole image, and shows the needs for improvement about the study curriculum in the future.

Table 6 shows the theme and results of "Opened up" lecture. In the theme of "Opened up" of the 4th course, the participant increased to 460 people. It, therefore, became clear that the incentive effect for a lot of participants to about half although "opened it up". This shows that there was a significant effect to obtain the whole image of the experiment in each field, and reveals the directionality of the study curriculum in the future.

\subsection{Science Camp}

That camp is an accommodation type of experience school of three days and two nights in summer season, which combined the experiment with lecture consisting mainly of a capacity of 15 people, with a focused on the photon science, using the experimental and accommodations facilities of the research institute of the KPSI of JAEA.

The enforcement contents are classified roughly into two parts and put the principal objective in strongly impressing it with a wonder of the nature world including the quantum-related expression in the exchange of energy and momentum about the basic principle such as wave motion nature and particulate nature of the light, actual survey of the speed of light, and a reflection and refraction phenomena of light. Another is the content about the advanced measurement apparatus adapting the principle of light. The main purpose is to make participant recognize the importance of measuring apparatus, such as laser, an oscilloscope, an optical semiconductor detector, and a spectroscope, for a participant to obtain a physical chemistry phenomenon through measurement devices in its hand by oneself.

The evaluation results on the lecture by the participants are shown in Figure 1. It is interesting to 
have obtained the evaluation results of high score with dye laser oscillation experiment. In recent years, the cooperation lectures have been also carried out which can link the $100 \mathrm{~km}$ away Tsuruga site (Fukui prefecture, Japan) to the Kizu site (Kyoto prefecture, Japan) with a communication line.

\subsection{Science Seminar}

In the normal science seminar, the transfer of information is only one way from a lecturer to an audience and it is pointed out that the reaction from the participant side cannot be feedback from the many aspects as the fault. The super science seminars, which is called as "S-cube", have been currently carried out by the JAEA, for the purpose of taking in an experiment everywhere during a lecture and aiming at improvement in degree of understanding to compensate such a fault, while making a lecture recording on DVD, as well as reusable content, by delivering it with local cable TV. This is why much knowledge and know-how for a number of promotion activities to improve the degree of understanding of science and technology can be accumulated in other candidates who were not able to participate in the seminar. Therefore, as for the examination of the contents of a demonstration experiment by the careful preparation and ingenuity of a performer, and the organizer, it is expected that the motivation for science education can be expanded very effectively, and deployment of experiment/workshop school, etc., the ingenuity of the organizer and/or examination of the scenarios, have suggested that it is also possible to increase its effectiveness.

\subsection{Science Club}

They are club activities that have been currently carried out since 2002 in the Science Museum of Photons. For the primary school children upper grades about 100 capacity, the site-visit, the choice of the research theme, the practice of an experiment and a research, summarizing experimental results, examination and discussion, the evaluation, the presentation of research results, with a series of flows for a long term of nine months; the science club is, so to speak, a program in order to let experience a virtual researcher.

After nine years, then graduates of those days turns into university students in the field of science and engineering, and there can be in the situation coming back to the science museum and the research institute as experiment volunteers and lecturers, it is almost with the example in which the circulation circle concerned with the science education consisting mainly of a science museum or a research institute is first formed and rotated, after the project started.

\subsection{Experiment booth-village}

A large-scale shopping center was selected as the target place, and the delivery type of experiment lecture based on a new project was held in 2007. The target is a general customer including the parent and children who happened to pass by chance. It was tried to search how the delivery type of experiment lecture that the science exhibitions and the KPSI sponsored was accepted from various aspects aiming. It became flourishing by the shopper in each experiment booth all day. The ratio of children of comparatively ten-year-old or less especially low age group exceeded 60 percent of all over the participants who were characterized by the high degree of the interest and eagerness concerning the science and technology understanding improvement activity.

In the embodiment in 2008 fiscal year, the total participants in each booth: 1320 people; a remarkable effect of the understanding improvement such as "interesting 95\%", "80\% that was able to be understood", "65\% that want to examine", " 94\% that want to participate if such a class will be held", and "88\% to which the interest and the concern for the science and technology increase" are achieved. As shown in Figure 2, the spirit of inquiry and the degree of understanding have also been improved greatly by using a scientific stage together in the case of experiment booth-village.

\subsection{Facility visiting research}

For the student on the specialty of science of a university of education, it is a program that aims at consciousness attachment as a future teacher's egg through investigation of a function of a science museum. On the impression after the attendance about an experiment classroom (for example; fuel cell), "it was pleasant" occupies most and it is almost equal to the ratio that "wants to participate" in this program again mostly. By the contents of an experiment, not less than 80 to $90 \%$ of support has been obtained about how to speak about the contents of the replication experiment, or a lecturer, and although we were concerned about lacking relative the degree of difficulty (a high school student object is assumed) of the curriculum which I chose at first, it is shown that it was suitable as contents. Moreover, it is shown that there was a significant effect of the experiment school, from the viewpoint of motivation, and it is indicated that "could find new things," $73 \%$ and $89 \%$ "which holding the interest has changed" and "has taken great and wide interest". Furthermore, "already interested in nature, science and technology" is for $98 \%$, whereas "heightened interest in nature, science and technology" was $91 \%$, and it is also expected about 
the students, with science speciality on pedagogy who already has high intellectual appetite consciousness, that the pronounced effects on motivation have been confirmed.

Exhibitions, theater, experiment and workshop etc., among the science museum resources can be estimated for general evaluation, were calculated overall assessment of the individual points and evaluated to be "very interesting" as five points, "interesting" as four points, "normal” as three points, "not very interesting as two points, and "not interesting" as one point. As a result, Theater > Experiments school $>$ Science zone of light (Exhibition) $>$ Technology zone of light (Exhibition) $>$ Entrance (exhibition) $>$ Laser laboratory (demonstration experiment) $>$ Rediscovery zone of light (exhibition) > Bird's-eye view map around Kizugawa city (exhibition) > Energy zone (nuclear and atomic energy), and theater and experiments school have been found to be effective tools to bring about the motive force.

\section{Discussions}

\subsection{Categorized features of several events from a functional view point}

We want to make participants experience a researcher image bodily, as the message which I want to convey from the research institute side; the "science" in a school and "research" in a research institute can be placed in the same line in a broad sense, and the deep attention must be paid to their activities and future development. Categorized features of several events, were, therefore, categorized into a few groups from a functional viewpoint.

4.1.1. Outreach activity type. The outreach activity type is useful for the presentation of new knowledge and the information, although it was evaluated to be slightly a low value on the motivation and the prototypical experience effect of this type which has been mainly supported by the public acceptance activity (PA) of the research institute. As shown in Table 5., from a viewpoint of the outreach activity development in a research organization and a university, the value of about 50 to 70 percent is indicated, and it is shown that the examination of the content of a further course is necessary as an attempt at coming the feeling of researchers at research laboratories and universities to obtain their real images. Moreover, it is shown to expect the effect of 80 to 90 percent to recognize the importance of the learning, from the viewpoint of the career education for bringing up the scientist.

4.1.2. Motivational type. From the motivational viewpoint, it is assumed to be effective of the 90 percent participants in the theme of "Flashed" that treats the Nobel Prize winning experience-based experiment, and about 80 percent in the theme of "Search" as shown in Table 5. Moreover, the participants of 60 percent or more were also achieving the self-culture effect of the learning. On the theme of "Search" of the 2nd course, the understanding level is comparatively high while the difficulty of the lecture content was also high, and, as a result, it is thought by strengthening the motivation that it leads to increase in interest in the science and technology and to bring about the improvement of the concern, because it was assumed to be an aim to make the student actually experience state-of-the-art experiment equipments (related to microscopes such as the laser scanning confocal microscope, the scanning electron microscope, and the atomic force microscope).

As compared with the case of normal dispatch lecture, that of the science-walker reveals the unique features as shown in Figure 3. The ratio (the total value of "excellent" and "good" to be evaluated), as shown in reverse triangular symbols in the figure, remarkably increased in the interests and concerns. Changes in the degree of motivation were also found to study and research in the science and technology field. The including ratio of the up-to-date contents tends to decrease, although the normal contents were examined enough. It is, therefore, pointed out as a future problem whether they can be obtained as a key content and be easily applied to the school spot or not.

4.1.3. Problem setup type. From the viewpoint of the problem oriented type activity, it is interesting to correlate the spirit of inquiry with the increase in degree of understanding, since the contents were planned to obtain a whole image. The spirit of inquiry reveals higher values than those of general experiments schools and this type activity brings about the incentive effect and strong impact for participants. In addition, even if significant motivation effect can be given, the greater its effect, it shows wide ranging effect on an inquiring mind and its influence spreads widely in career education.

4.1.4. Problem solution type. In practice examples on the "photon science club" for primary school students or the "science camp" for high school students, it continues for a long period of time (nine months for a science club) or for a condensed period of time (three days stay for a science camp), the participants are going to select any theme freely and to get the final draft towards the solution, and lead to future researcher training and science lover children's training by managing the virtual experience in connection with a series of "mini-research activities" which consists of summarizing obtained results, reviewing and presentation. Although each marks 
also have many portions to be reviewed, the effects of "circulation circle" that assume science to be "relaxation space" of the life regardless of an age or a target begin to emerge by practice of the sustainable activities for eight to nine years.

In the example of a photon science club, the student who received lecture and instruction in lower grade, come back and join as a new lecturer, an experiment volunteer staff and/or a leader, in the large circle of understanding and promotion of science and technology, which begins to be active as the key member with growth. Several issues to be solved are pointed out,

(1) long-term assistance in the operation can be also required,

(2) a short-term result is hard to be obtained,

(3) effect evaluation in the middle of the support is necessary for administration.

4.1.5. Edutainment type. As for the last "edutainment type", a research institute and a science museum, in a broad sense, realize it as the place enjoying science as a whole and accepting the demands of participants while the museum staff and participants communicate and interact through a booth form with each other. The Heijo-kyo Festival 1300 anniversaries (transfer-of-the-capital 1300 years ago) etc. tried "the liberal arts - science and technology fusion approach" which united science with local, hometown and native cultures. As a result, the understanding degree of contents is not a sufficient high value, since the outline was not systematically presented as a whole image. However, the motivation, prototypical experience effect, even in terms of new findings, show favorable evaluation values as compared with those in other practice examples. This reveals the possibility of a local science museum and a research institute, in cooperation with the school spot, to act and provide us with the know-how and the methodology of demonstration experiments, besides the indication about the importance of "learning it enjoying itself" that corresponds to the origin regression on experiment schools.

\subsection{Corporation with local communities such as local government, educational institute, school and public sectors}

4.2.1. Community life. From a viewpoint of the local symbiosis activity from the perspective of the region and the community life, the impression "that was good" and the formation of (a) motivation which it supposes "I would like to participate if there is such a lesson", and of (b) hands-on experience of the wonder and fun, are the most characteristic features in the science festival in Yamashiro, which are cooperation / fusion plans with the Kyoto Yamashiro Education Bureau and the Wide Area Planning and
Promotion Bureau which are administrative bodies. At these Science Festivals for children and the public, it especially turns out, that new discovery and a large increase in the interest and concern in science and technology have been obtained.

Trial concept of "the science walker" that is in a new fusion form of an experiment booth-village and a dispatch lecture (visiting lecture) can be applied to a science festival as every year event or an unique and other science festival in Yamashiro. Those events are also aimed at practicing interesting experiments lecture having fun, and at planning the outdoors experiment stages consisting of physical, chemical and electro-magnetic experiments in the former festival, and at setting a theme to "tea" as a famous local agricultural product in the latter festival. Our approach has not plan to make upsurge of a participant's sense of purpose beforehand although sufficient evaluation-of-effectiveness result is not yet obtained, since the growth of the increase in visitors was insufficient for both cases. New discovery and significant increase in interests and concerns about science and technology are brought about to a higher level as compare with other events, as a result, the effective motivation effect can be obtained.

4.2.2. Social cooperation. In the in-service training seminar for teachers practiced from the viewpoint of social cooperation type activity, it seems that the degree of understanding in connection with the contents increased greatly, although the request was still proposed on the practical contents which can be immediately applied to the school spot, from the situation of teaching-materials development. As for the new attempt, concepts and ideas were also introduced by the visiting lecturer on the know-how in the materials development, for the provision of expertise, and on its application that can be used by using familiar material as much as possible. These offer an opportunity to also make teachers realize the importance for how to communicate with children, who can taste pleasure peculiar to experiments school, and how to pass the information about such contents on to the children. Furthermore, it is thought that significant results can be obtained as efforts to bridge the gap between researchers and the community by the cultural exchange with teachers and the JAEA researchers in the nuclear field who were in charge of instruction.

\subsection{Effects of cooperation and superposition on the cooperated and united planning}

The outline of the cooperated and united planning to be performed was summarized in Figure 4. In the science festival and in-service training seminar for teachers, which are cooperation and fusion plans 
with the Yamashiro Education Bureau and/or Yamashiro Wide-area Promotion and Development Bureau that are local government administrative organization, it is discriminative to be represented by the impression of comments of "good or excellent", and (a) the motivation (incentive) that means "would like to participate if there is such a lecture", and (b) experiences made by wonder and/or amusement. Children and the general public are subject to the target people for presentation and performance as for the science festival, and also teachers in the inservice training for teachers. It can be seen that participants can have new discovery and obtain large increases in interests and concerns of science and technology because of (c) a clear sense of purpose for training.

In addition, in case of the super science walker, which corresponds to a new united form of an experiment booth village to a dispatch lecture (visiting lecture), it can be seen that new discovery and large increases in interests and concerns about science and technology bring about a significant learning effect, although these events are not beforehand intended to upgrade a participant's sense of purpose beforehand, as compared with other conventional events.

As for the results of analysis of other events, the planed exhibitions and the parent-child experimental lectures make much account of (d) entertainment characteristics based on "the pleasure" in various kinds of experiments schools, workshops and a scientific stage, whereas the S-Cube (Super Science Seminar), site-visit lesson such as the facility visiting research or the Super Science High school (SSH) aim at the motivation or formative experiences besides the acquisition of new knowledge and think of as the main point of (e) the degree of understanding or the spirit of inquiry in place of entertainment characteristics as shown in Figure 5.

In the case of SSH, it shows that the further actions are also necessary to both (d) entertainment characteristics and (e) the degree of understanding or the spirit of inquiry. Among these, the case study of facility visiting research revealed the well-balanced state in both cases, and these were kept to be high scores. It has shown that an important impact is observed due to the participant's high sense of purpose. From such a result, it is pointed out that (f) the necessity for prior learning and the upsurge of a sense of purpose are effective for the further increase of the learning effect in the science education.

\section{Conclusions}

The basic data about the superposition effect and the cooperation effect were obtained based on the feature and the effect. The useful data was also acquired about characteristics of each component, an effect, methodology, and contents of a program viewed from experimental technique.

The contents of these activities on understanding of science and technology were classified into five types;

(1) "Outreach activity type" that combined with introduction of the cutting-edge research,

(2) "Motivational (hands-on) type" based on experiments training,

(3) "Problem setup type" to grasp the whole image of contents, through several times experiment schools,

(4) "Problem solution type" to summarize and evaluate short period or long-term research results, and to compete with presentation of results, based on the viewpoint of improvement in consciousness through multiple research and career education, and

(5) "Edutainment type" to experience the pleasure of science experiments.

About five models classified above,

(1) Outreach activity type has a significant effect on participants' motivation, and interest and concerns in science and technology is further heightened by the introduction of new methodologies and presentation.

(2) In case of motivational (hands-on) type, new issues to be solved are proposed whether the content can be easy to apply at school spots, while including new contents. And furthermore, extremely high values were obtained that mean the degree of understanding; 70-90\%, motivation effects and discovery; over $90 \%$, and prototypical experience effect; over $80 \%$, by the in-service teacher training.

(3) With the problem setup type, the issues are summarized from the viewpoint of trigger (touched off), search, flashed and opened up types. Moreover, as for the motivation and the prototype experiences effect, the "search" type was the most effective and had a large impact on career education. In addition, the "opened up" type of lecture brought about higher effective motivation, as compared with that of "flashed" type, in terms of the importance of learning and career education.

(4) In the problem solution type, the "the circulation circle", which assumes science to be living and relaxation space of the life, is being formed across the generation and an object by the sustainable practice activities for many years such as a science club and science camp.

(5) With the edutainment type, some trial approaches of "the liberal arts - science and technology fusion approach" have been carried out which united science with local, hometown and native cultures, in such a case of "The Heijo-kyo Festival 1300 anniversaries (transfer-of-the-capital 1300 yeas ago)” held at Nara prefecture, as a result, the remarkable promoting effects on understanding science and technology were also obtained in respect of motivation and the prototypical experience effect. 
It was considered as the way the science museum staff and a participant can make mutual communication through the experimental booth form. High rating to be evaluated was revealed us in respect of motivation, the prototypical experience effect, and new discovery.

This has shown a possibility that the local science museum can cooperate with the school spot, and also act as presentation of the know-how (expertise) and the methodology for demonstration experiments besides the pointing out the importance of "learning it while having pleasure" which corresponds to revolution on an experiment school to a starting point.

Promotion activity on understanding of science and technology is mainly imposed on a role as the key interface between a research and general society by cooperating with the local administration, educational institution, and schools while coping with different kinds of purposes about several targets; improvement of relations between parent and child (for infant), an incentive (for the lower grade), a search of the mystery (for primary and/or secondary student), a real experience (for high school student), a class and/or lecture (for university student), in-service training (for teacher) and the outreach activity (for general person) as shown in Figure 6.

It is important to bring up new idea, and to improve and raise the originality and creativity, whether younger people can acquire real experience to contact with the wonder of science from the scientific viewpoint or not. There are many places that can be experienced to develop "Heart of
Science" through KSMP and KPSI, where an experiment school on the energy conversion and environments, science seminar (S-cube) and the trial of the leading experiment and/or work school including the "experiment booth-village" and the "science-walker" have also been carried out and can provide us with a breakdown based on recent results of research in the KPSI of JAEA, which make an important role as "a rest and joints salon" relating results of research with general persons.

\section{Acknoledgement}

This work was partly supported by Grant-in-Aid for Scientific Research (C) project No. 21500857 (lead researcher: Taiji Hoshiya) from Japan Society for the Promotion of Science (JSPS).

\section{References}

[1] K. Takahashi eds, "Promotion of the science mediator system”, The 2003-2004 th research report on the Special Coordination Funds for Promoting Science and Technology, in Japanese, The ministry of education, culture, sports, science and technology-Japan (MEXT), Tokyo, Japan, March 2005, pp. 1- 225.

[2] T. Hoshiya and M. Nisikawa, The fourth text on 2009 in-service training seminar for teachers, in Japanese, KPSI of JAEA and the Yamashiro Educational Institution, Kyoto, Japan, March 2010, pp.1 - 284.

Table 1. The outline of curriculums on "Wonder of the light" in the field of photon science for younger students

\begin{tabular}{|c|c|c|c|c|}
\hline \multirow{2}{*}{ No. } & \multicolumn{2}{|c|}{ Energy Conversion } & \multirow{2}{*}{ Experiments } & \multirow{2}{*}{ Remarks } \\
\hline & Before & After & & \\
\hline \multirow{3}{*}{$1 \mathrm{st}$} & \multirow{3}{*}{ Optical } & Thermal & Infrared light effects & $\begin{array}{l}\text { Thermal radiation \& } \\
\text { communication }\end{array}$ \\
\hline & & Chemical & $\begin{array}{l}\text { Ultraviolet light \& } \\
\text { chemical effects }\end{array}$ & $\begin{array}{l}\text { Sterilizing effects \& } \\
\text { vitamin C }\end{array}$ \\
\hline & & Electrical & $\begin{array}{l}\text { Visible light \& } \\
\text { excitation effect }\end{array}$ & $\begin{array}{l}\text { Dye-sensitized } \\
\text { solar cell }\end{array}$ \\
\hline \multirow{3}{*}{ 2nd } & Thermal & \multirow{3}{*}{ Mechanical } & $\begin{array}{l}\text { Energy-conversion } \\
\text { materials }\end{array}$ & $\begin{array}{l}\text { Shape memory } \\
\text { alloy }\end{array}$ \\
\hline & $\begin{array}{l}\text { Electrical- } \\
\text { magnetic }\end{array}$ & & Faraday's experiment & Lorentz force \\
\hline & Physical & & $\begin{array}{l}\text { Steam engine \& } \\
\text { conversion ratio }\end{array}$ & Saving energy \\
\hline \multirow{3}{*}{ 3rd } & \multirow{3}{*}{ Chemical } & Biological & $\begin{array}{l}\text { Termitidae \& } \\
\text { protozoa }\end{array}$ & $\begin{array}{l}\text { Foot print } \\
\text { pheromone }\end{array}$ \\
\hline & & Electrical & $\begin{array}{l}\text { Sir Grove's } \\
\text { experiments }\end{array}$ & Fuel cell \\
\hline & & Electrical & $\begin{array}{l}\text { Energy-conversion } \\
\text { materials }\end{array}$ & $\begin{array}{l}\text { Electrically } \\
\text { conducting plastics }\end{array}$ \\
\hline \multirow{3}{*}{ 4th } & Physical & Electro-magnetic & $\begin{array}{l}\text { Morse / Marconi's } \\
\text { experiments }\end{array}$ & Radiotelegraphy \\
\hline & Thermal & Magnetic & $\begin{array}{l}\text { Energy-conversion } \\
\text { materials }\end{array}$ & $\begin{array}{l}\text { High temperature } \\
\text { superconductors }\end{array}$ \\
\hline & Electrical & Thermal/Optical & $\begin{array}{l}\text { Switching on a light \& } \\
\text { emission of a light }\end{array}$ & $\begin{array}{l}\text { Plasma at near } \\
\text { atmospheric } \\
\text { pressure }\end{array}$ \\
\hline
\end{tabular}


Table 2. Results of questionnaire of in-service training seminar for teachers

\begin{tabular}{|c|c|c|c|c|c|c|c|c|}
\hline \multirow{2}{*}{ QUESTIONNAIRE } & \multicolumn{2}{|c|}{ OUT REACH } & \multicolumn{2}{|c|}{ PRACTICE EXPERIENCE } & \multicolumn{2}{|c|}{$\begin{array}{l}\text { TEACHING MATERIALS DEVELOPMENT } \\
\text { \& LESSON IMPROVEMENT }\end{array}$} & \multicolumn{2}{|c|}{ EDUTAINMEN } \\
\hline & YES & NO & YES & NO & YES & NO & YES & NO \\
\hline IMPRESSION (ENJOYED OR NOT) & $73 / 93$ & $3 / 3$ & $100 / 90$ & $0 / 0$ & $94 / 88$ & $0 / 0$ & 97 & 0 \\
\hline EXPLANATION (EASY TO UNDERSTAND OR NOT) & & & $94 / 90$ & $0 / 0$ & $72 / 88$ & $0 / 0$ & 77 & 16 \\
\hline MOTIVATION (WANTED TO PARTICIPATE AGAIN OR NOT) & $87 / 90$ & $3 / 7$ & $100 / 100$ & $0 / 0$ & $94 / 100$ & $0 / 0$ & 94 & 0 \\
\hline (CHANGED IN INTERESTS IN EXPERIMENTAL FIELD OR NOT) & $87 / 90$ & $3 / 0$ & $94 / 90$ & $0 / 0$ & $89 / 94$ & $0 / 0$ & 90 & 0 \\
\hline EXPERIENCE-BASED RESULTS (ALREADY INTERESED IN NATURE \& SCIENCE OR NOT) & $77 / 80$ & $10 / 10$ & $100 / 90$ & $0 / 0$ & $83 / 88$ & $11 / 6$ & 58 & 19 \\
\hline PRACTICE EXPERIENCE (INCRESED IN NATURE \& SCIENCE OR NOT) & $77 / 93$ & $3 / 3$ & $94 / 90$ & $0 / 0$ & $83 / 100$ & $0 / 0$ & 94 & 0 \\
\hline \begin{tabular}{|l} 
DISCOVERY \\
(FOUND A NEW THING OR NOT)
\end{tabular} & $83 / 93$ & $3 / 3$ & $94 / 70$ & $0 / 0$ & $89 / 100$ & $6 / 0$ & 90 & 0 \\
\hline APPLICATION (ANY CONTENTS THAT CAN BE APPLIED TO LESSON OR NOT) & $67 / 77$ & $3 / 3$ & - & - & $75 / 88$ & $5 / 0$ & - & - \\
\hline
\end{tabular}

Table 3. Results of questionnaire of the dispatch lecture (delivery type) to be associated with local high school in Yamashiro area, Kyoto, Japan

\begin{tabular}{|c|c|c|c|c|c|c|c|c|c|}
\hline \multirow{3}{*}{$\begin{array}{c}\text { THEME } \\
\text { QUESTIONNAIRE }\end{array}$} & \multicolumn{2}{|c|}{$\begin{array}{l}\text { HYDROSPHERIC ENVIRONMENT, } \\
\text { MATERIALS CIRCULATION }\end{array}$} & \multicolumn{2}{|c|}{ FUEL CELL, NYLON SYNTHESIS } & \multicolumn{2}{|c|}{$\begin{array}{l}\text { ENERGY DEVELOPMENT, RADDATION, } \\
\text { THEORY OF EVOLUTION }\end{array}$} & \multicolumn{3}{|c|}{$\begin{array}{l}\text { CATALYST, SELF-REGENERATION, } \\
\text { SYNCHROTRON RADIATION }\end{array}$} \\
\hline & \multicolumn{2}{|c|}{ 1st } & \multicolumn{2}{|c|}{ 2nd } & \multicolumn{2}{|c|}{$3 \mathrm{rd}$} & \multicolumn{3}{|c|}{ 4th } \\
\hline & YES & NO & YES & NO & YES & No & YES & & \\
\hline \begin{tabular}{|l} 
IMPRESSION \\
(ENNOYED OR NOT) \\
\end{tabular} & 15 & 12 & 59 & 3 & 37 & 14 & 50 & & \\
\hline EXPLANATION (EASY TO UNDERSTAND OR NOT) & 35 & 12 & 43 & 3 & 24 & 22 & 47 & & \\
\hline MOTIVATION (WANTED TO PARTIIIPATE OR NOT) & 27 & 15 & 48 & 8 & 37 & 18 & 41 & & \\
\hline WLLLNGNESS TO LEARN (WANTED TO GET THESE LECTURES OR NOT) & 8 & 31 & 41 & 13 & 39 & 20 & 34 & & \\
\hline PRACTICE EXPERIENCE (WAS ALREADY INTERESTED OR NOT) & 42 & 35 & 52 & 11 & 63 & 16 & 46 & & \\
\hline (INCREASED IN INTEREST AND CONCERN OR NOT) & 15 & 19 & 34 & 11 & 35 & 18 & 41 & & \\
\hline (DISCOVERYED A NEW THING OR NOT) & 42 & 8 & 43 & 10 & 37 & 14 & 47 & & \\
\hline UNDERSTANDING (UNDERSTOOD FOR MYSELF OR NOT) & 46 & 12 & 59 & 8 & 37 & 24 & 53 & & \\
\hline EXAMINING MIND (WANTED TO EXAMINE BY MYSELF OR NOT) & 0 & 35 & 18 & 30 & 18 & 33 & 26 & & \\
\hline 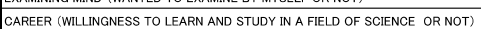 & 35 & 23 & 34 & 23 & 43 & 18 & 33 & & \\
\hline SCORE OF "LECTURE" & & & & & & & \multicolumn{3}{|c|}{$\frac{1}{3.12}$} \\
\hline \multirow{3}{*}{ SCORE OF "EXPERIMENTS BY LECTURER" } & \multirow{3}{*}{\multicolumn{2}{|c|}{0.58}} & & & \multicolumn{2}{|c|}{ ENERGY DEVELOPMENT } & \multirow{3}{*}{\multicolumn{3}{|c|}{ PLATINUM CATALYST }} \\
\hline & & & & & $\begin{array}{l}\text { RADIATION, THUI } \\
\end{array}$ & 3. & & & \\
\hline & & & & & THEORY OF EVO & DNMENT 3. & & & \\
\hline SCORE OF "PRACTICE (EXPERIENCE) EXPERIMENTS" & & & \multicolumn{2}{|c|}{ NYLON SYNTHESIS 3.36} & & & & & \\
\hline
\end{tabular}

Table 4. Results of questionnaire of another example of a coordinated lecture concerning the energy of light with students of the primary school for same area as a reference

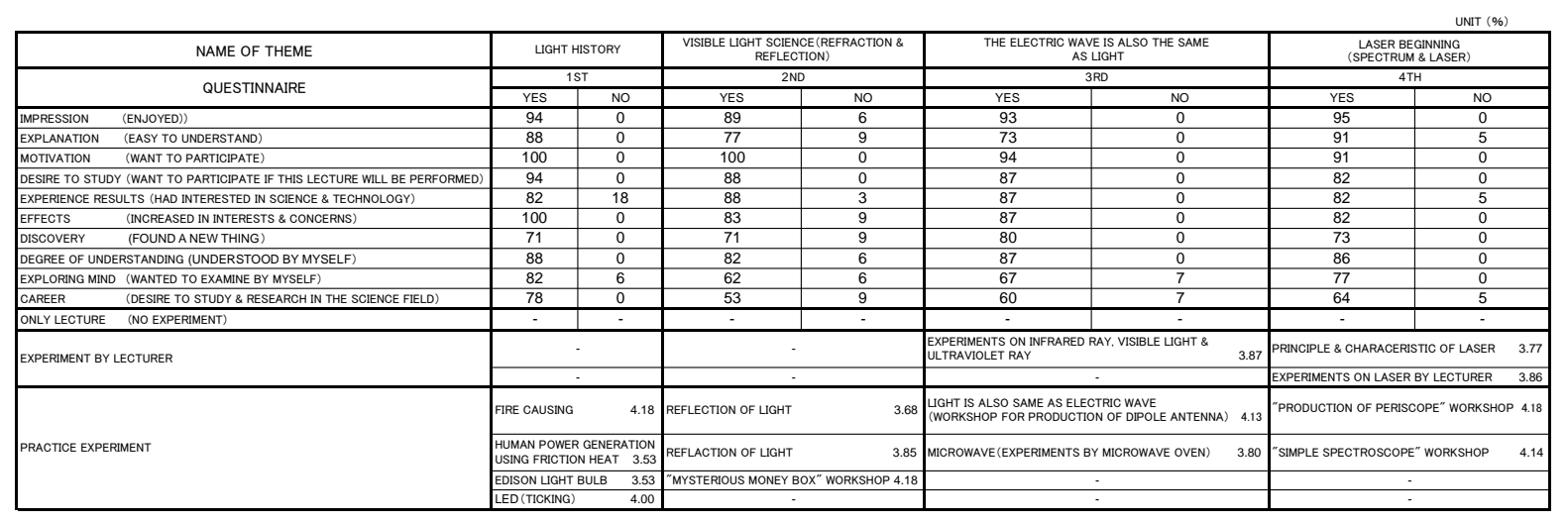


Table 5. The summary of questionnaire on dispatch lectures. Changes in the degree of motivation in the field of the science were easily obtained in these lectures

\begin{tabular}{|c|c|c|c|c|c|c|c|c|}
\hline THEME & \multicolumn{2}{|c|}{ TOUCHED OFF } & \multicolumn{2}{|c|}{ SEARCH } & \multicolumn{2}{|c|}{ FLASHED } & \multicolumn{2}{|c|}{ OPEND UP } \\
\hline CONTENTS & \multicolumn{2}{|c|}{ EXPERIMENT BOOTH-VILLAGE } & \multicolumn{2}{|c|}{$\begin{array}{c}\text { SEEING IS BELIEVING } \\
\text { (MICROSCOPE) }\end{array}$} & \multicolumn{2}{|c|}{$\begin{array}{c}\text { VIRTUAL SCIENTIST } \\
\text { (NOBEL PRIZE MEMORIAL } \\
\text { EXPERIENCE) } \\
\end{array}$} & \multicolumn{2}{|c|}{$\begin{array}{l}\text { MAPPING SCIENCE } \\
\text { (WHALL IMAGE) }\end{array}$} \\
\hline \multirow{2}{*}{ QUSTIONNAIRE } & \multicolumn{2}{|c|}{ 1ST } & \multicolumn{2}{|c|}{ 2ND } & \multicolumn{2}{|c|}{ 3RD } & \multicolumn{2}{|c|}{$4 \mathrm{TH}$} \\
\hline & YES & NO & YES & NO & YES & NO & YES & No \\
\hline DID YOU LIKE EXPERIMENTS \& WORKSHOP SCHOOL OR NOT & - & - & 86 & 14 & 92 & 0 & 66 & 6 \\
\hline \multicolumn{9}{|l|}{\begin{tabular}{|l} 
IMPRESSIONS AFTER LECTURE \\
\end{tabular}} \\
\hline$\cdot$ INTERESTING OR NOT & 78 & 4 & 90 & 0 & 100 & $\mathbf{0}$ & 59 & 4 \\
\hline -DIFFICULT OR NOT & - & - & 48 & 33 & 46 & 23 & 28 & 22 \\
\hline -EASY TO UNDERSTAND OR NOT & 91 & 0 & 86 & 14 & 100 & 0 & 57 & 6 \\
\hline WILLINGNESS TO LEARN (WANTED TO GET THESE LECTURE OR NOT) & 70 & 4 & 90 & 5 & 92 & 0 & 61 & 8 \\
\hline EXAMINING MIND (WANTED TO EXAMINE BY MYSELF OR NOT) & 65 & 4 & 62 & 5 & 92 & 0 & 32 & 10 \\
\hline DISCOVERY (FOUND A NEW THINGS OR NOT) & - & - & 67 & 5 & 92 & 0 & 63 & 6 \\
\hline INTERESTS (HAD INTERESTS IN NATURE AND SCIENCE \& TECHNOLOGY OR NOT) & - & - & 86 & 10 & 92 & 0 & 56 & 20 \\
\hline EFFECTS (INCREASED IN INTERESTS \& CONCERNS IN A FIELD OF SCIENCE OR NOT) & 78 & 0 & 81 & 5 & 92 & 0 & 50 & 7 \\
\hline CAREER (WILLINGNESS TO STUDY AND RESEARCH IN A FIELD OF SCIENCE OR NOT) & - & - & 52 & 14 & 92 & 0 & 42 & 19 \\
\hline \multicolumn{9}{|l|}{ WHAT YOU HAVE LEARNED } \\
\hline - POWER TO PARTICIPATE IN OPINION RESPECT AND DISCUSSION & 65 & 30 & 35 & 65 & 92 & $\mathbf{0}$ & 32 & 31 \\
\hline -POWER TO WORK IN COLLABORATION WITH ROLE SHARING & 57 & 22 & 65 & 24 & 92 & 0 & 30 & 36 \\
\hline -METHOD \& POWER ON INFORMATION-GATHERING AND UTILZATION & 78 & 9 & 71 & 24 & 83 & 8 & 40 & 27 \\
\hline - POWER TO THINK DEEPLY & 65 & 22 & 65 & 35 & 92 & 0 & 55 & 22 \\
\hline -METHOD \& POWER TO DISCUSS, EXPLAIN \& CREATE A REPORT & 70 & 13 & 65 & 29 & 83 & 8 & 38 & 32 \\
\hline CAME TO FEEL FAMILIAR TO RESEARCHER OR NOT & 70 & 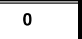 & 71 & 0 & 92 & 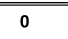 & 38 & 18 \\
\hline HAD A CONCRETE IMAGE ABOUT RESEARCH OF UNIVERSITY \& INSTITUTE OR NOT & 57 & 4 & 53 & 6 & 100 & 0 & 48 & 15 \\
\hline DID YOU THINK THAT LEARNING IS IMPORTANT, SCINCE IT IS NEEDED IN THE FUTURE OR NOT & 82 & 13 & 95 & 6 & 91 & 0 & 80 & 16 \\
\hline DID YOU THINK THAT IT WAS CHALLENGING, SCINCE A FUTURE POSSIBILITY IS EXTENDED OR NOT & 87 & 9 & 94 & 6 & 91 & 0 & 82 & 14 \\
\hline DID YOU WANT TO GET AN OCCUPATION TO NEED SCIENCE OR NOT & 69 & 22 & 82 & 18 & 100 & 0 & 64 & 31 \\
\hline UNDERSTOOD THAT THE WAY OF THINKING CAN BE UTILIZED IN VARIOUS FIELD OF SOCIETY OR NOT & 78 & 4 & 88 & 0 & 100 & 0 & 53 & 8 \\
\hline UNDERSTOOD THE IMPORTANCE OF LEARNING OR NOT & 83 & 0 & 88 & 0 & 92 & 0 & 50 & 6 \\
\hline
\end{tabular}

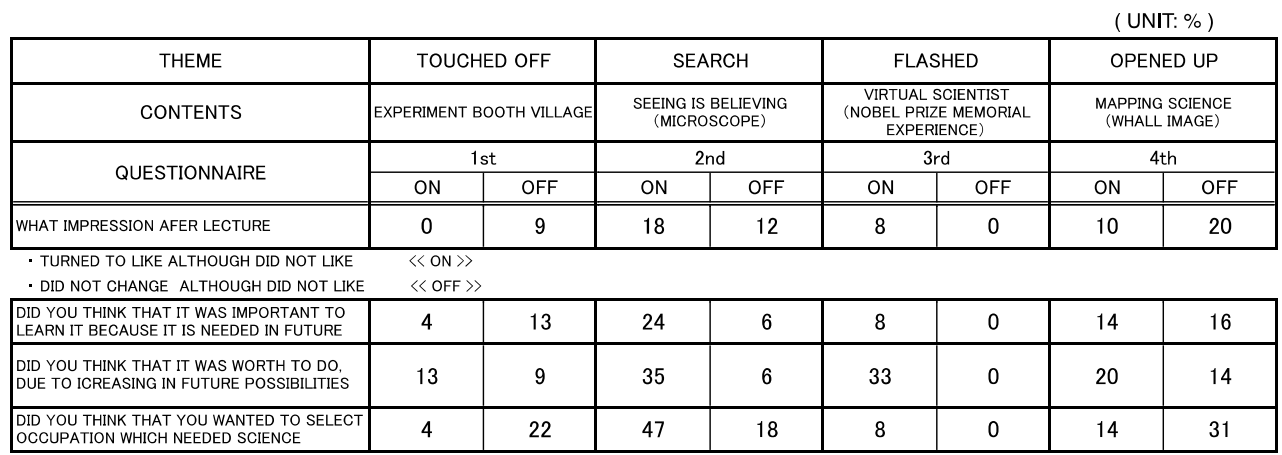

YOU WANTED TO

CHNGED TO THINK, ALTHOUGH DID NOT THINK $\langle\langle O N\rangle$

CHANGE, ALTHOUGH DID NOT THINK 《OFF》

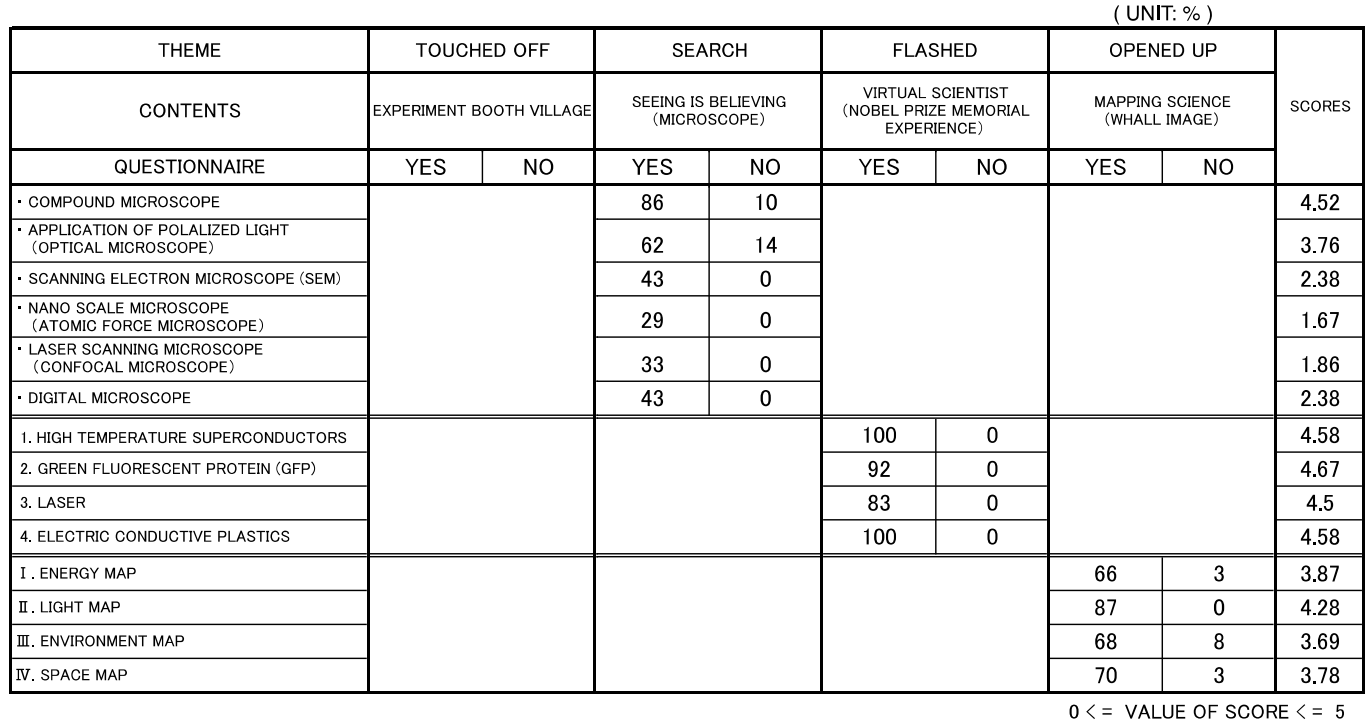


Table 6. The theme and results of "Opening up" lecture in the science-walker. In the theme of "Opening up" of the 4th course, the participant increased to 460 people as junior high school students

\begin{tabular}{|c|c|c|c|c|c|c|c|c|c|}
\hline \multirow{2}{*}{$\begin{array}{c}\text { THEME } \\
\text { QUESTION }\end{array}$} & \multicolumn{2}{|c|}{ ENERGY } & \multicolumn{2}{|c|}{ LIGHT } & \multicolumn{2}{|c|}{ ENVIRONMENT } & \multicolumn{3}{|c|}{ SPACE } \\
\hline & YES & NO & YES & NO & YES & NO & YES & NO & UNKNOWN \\
\hline DO YOU LIKE EXPERIMENTS AND WORKSHOP & 68 & 6 & 68 & 3 & 66 & 5 & 63 & 6 & 4 \\
\hline \multicolumn{10}{|c|}{ IMPRESSIONS AFTER LECTURE } \\
\hline INTERESTED OR NOT & 69 & 5 & 78 & 3 & 68 & 9 & 21 & 0 & 57 \\
\hline DIFFICULT OR NOT & 38 & 26 & 28 & 29 & 23 & 31 & 21 & 4 & 54 \\
\hline UNDERSTOOD OR NOT & 66 & 8 & 72 & 6 & 72 & 7 & 19 & 4 & 60 \\
\hline $\begin{array}{l}\begin{array}{l}\text { WANTED TO PARTICIPATE OR NOT IF THIS } \\
\text { LECTURE WILL START }\end{array} \\
\end{array}$ & 66 & 9 & 71 & 6 & 55 & 8 & 53 & 10 & 6 \\
\hline WANTED TO EXAMINE BY MYSELF OR NOT & 42 & 14 & 40 & 15 & 31 & 9 & 14 & 4 & 60 \\
\hline DISCOVERED NEW THINGS OR NOT & 62 & 9 & 65 & 4 & 57 & 7 & 70 & 1 & 5 \\
\hline $\begin{array}{l}\text { INTERESTED IN NATURE, SCIENCE AND } \\
\text { TECHNOLOGY OR NOT }\end{array}$ & 60 & 22 & 56 & 18 & 57 & 20 & 52 & 17 & 4 \\
\hline $\begin{array}{l}\text { INCREASED IN INTERESTS AND CONCERNS } \\
\text { ON SAIENCE AND TECHNOLOGY OR NOT }\end{array}$ & 58 & 11 & 62 & 4 & 50 & 9 & 28 & 4 & 43 \\
\hline $\begin{array}{l}\text { WILLING TO LEARN OR STUDY IN THE FIELDS } \\
\text { OF SCIENCE }\end{array}$ & 44 & 20 & 47 & 15 & 39 & 22 & 40 & 17 & 6 \\
\hline
\end{tabular}

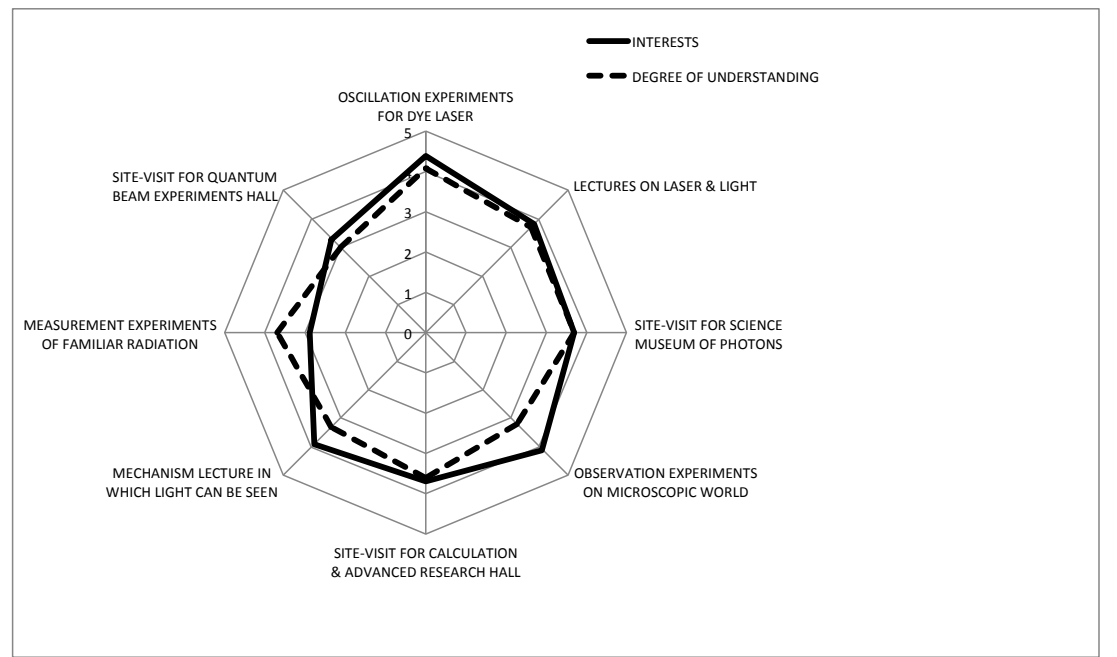

Figure 1. Changes in the degree of understanding and interests in the case of the science camp in FY 2006

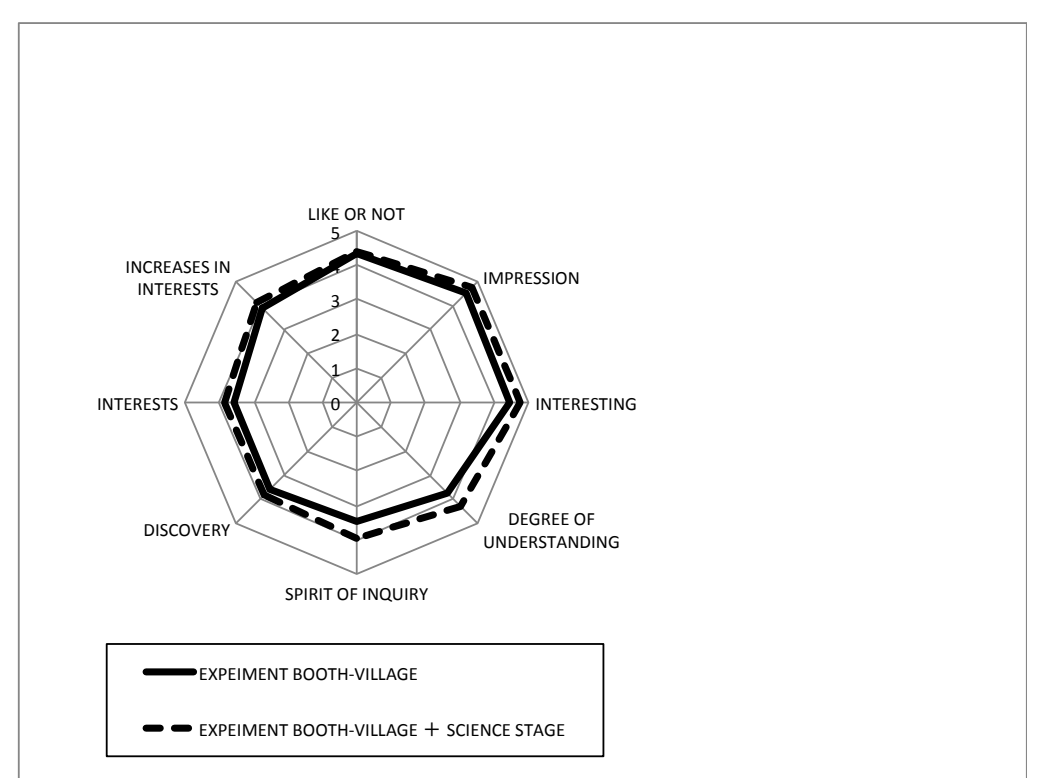

Figure 2. Changes in the degree of motivation in the experiment booth-village before and after science stage 


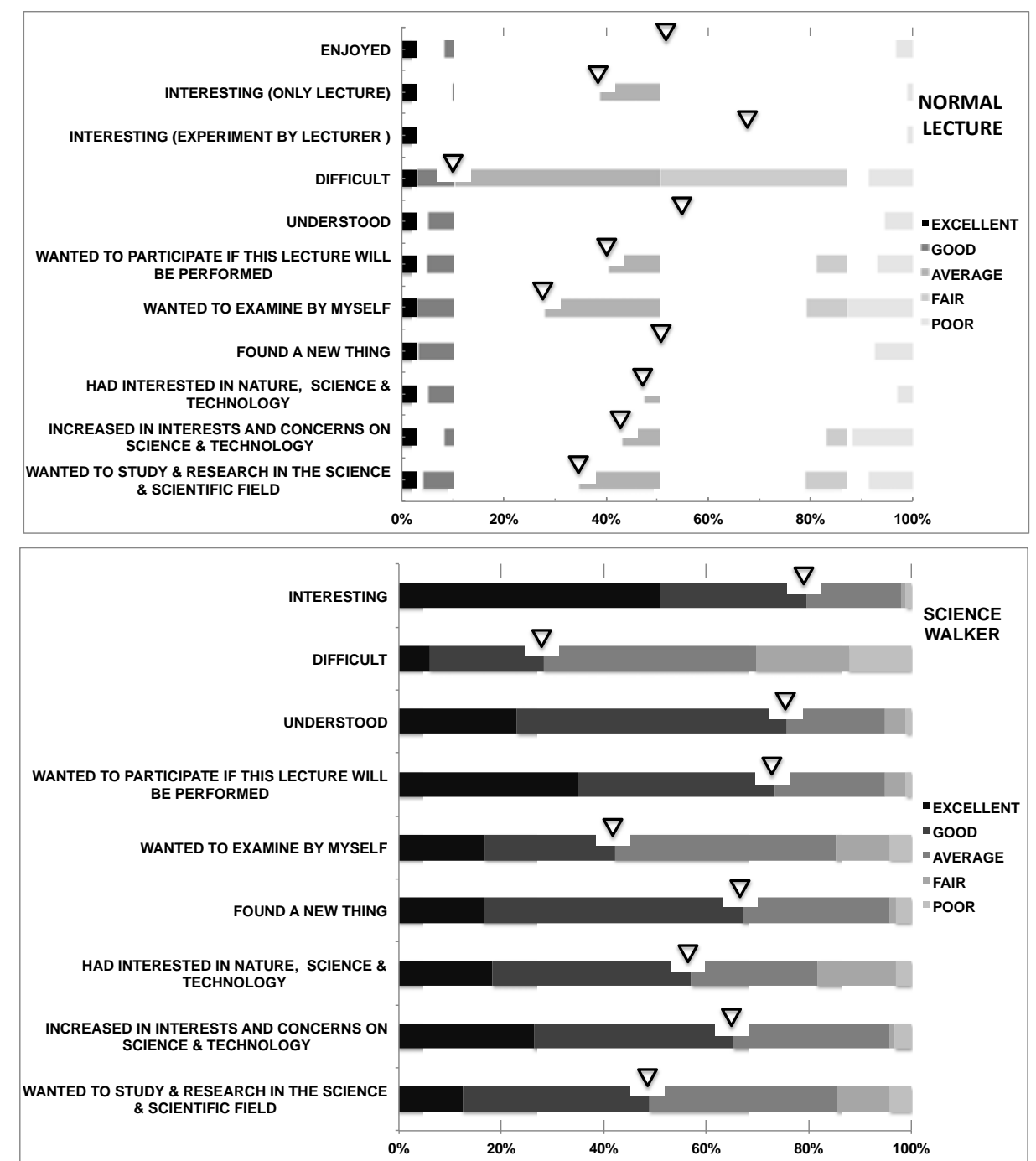

Figure 3. Differences in the degree of motivation between normal lecture and science walker were also found to study and research in the science and technology field

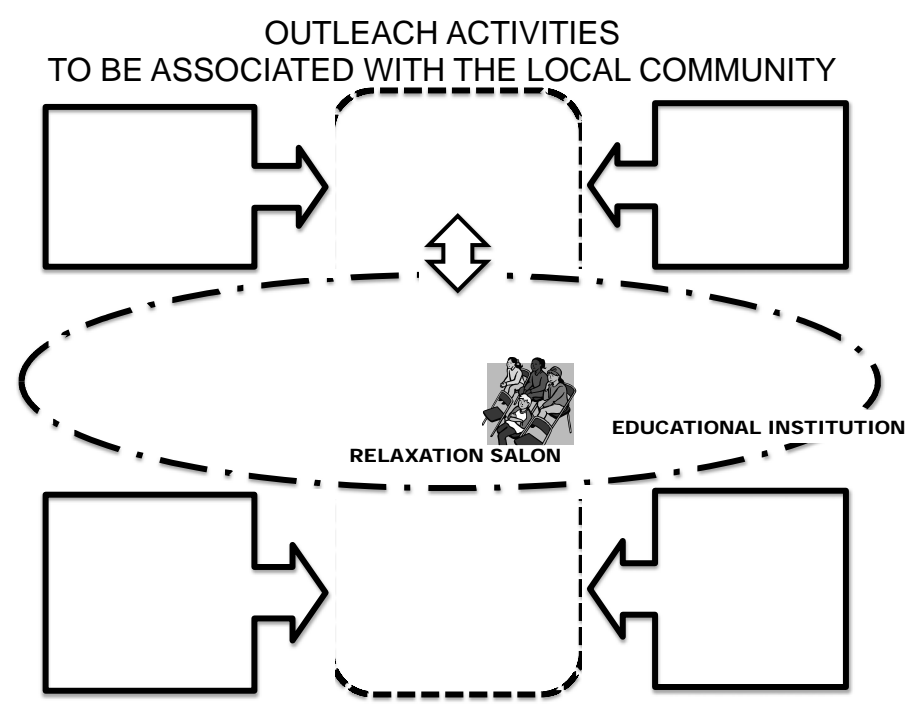

Figure 4. Outline of the outleach activities to be associated with the local community 


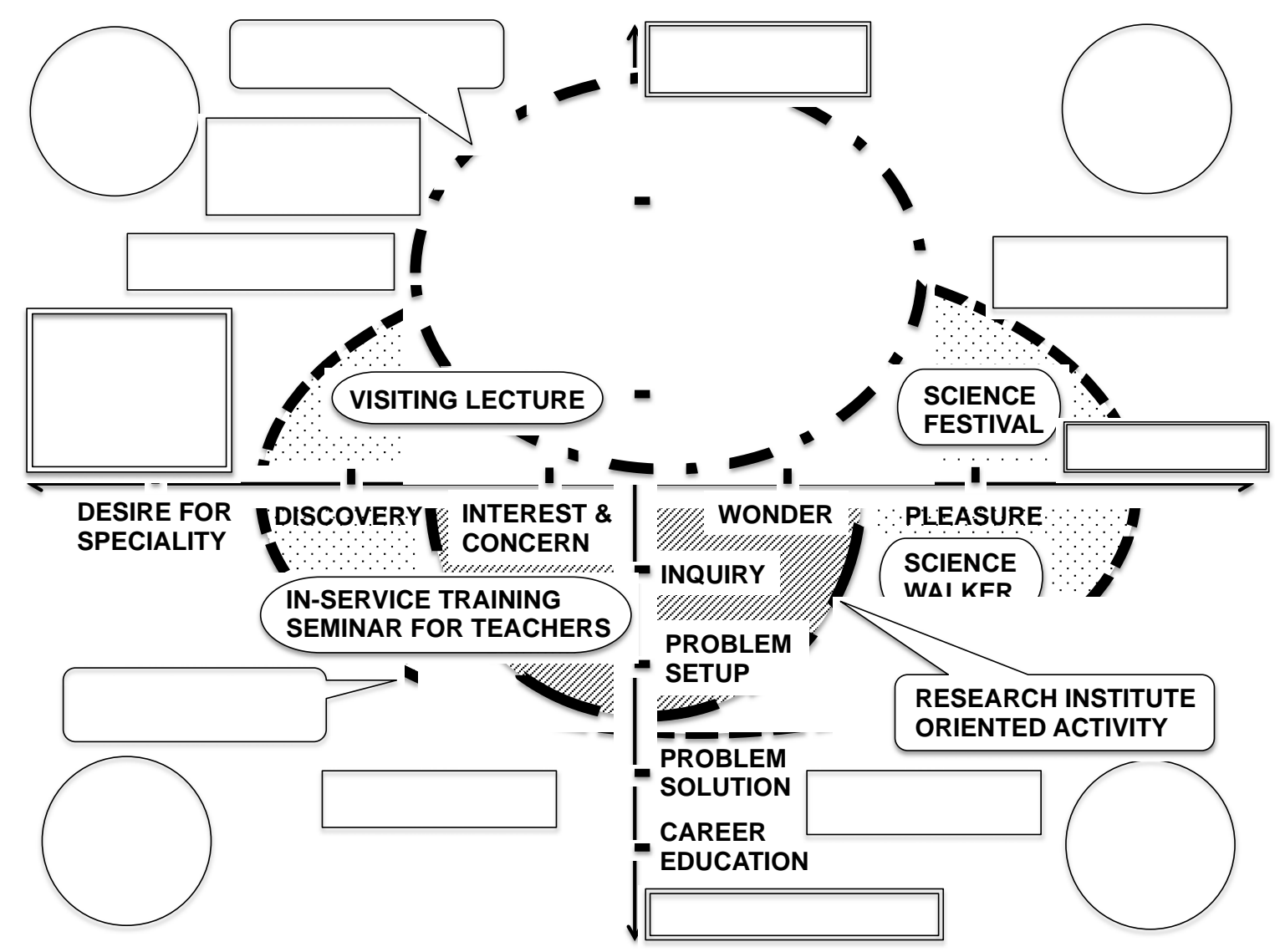

Figure 5. Conceptual chart on the cooperated and united planning and promoting events to be performed in FY 2008

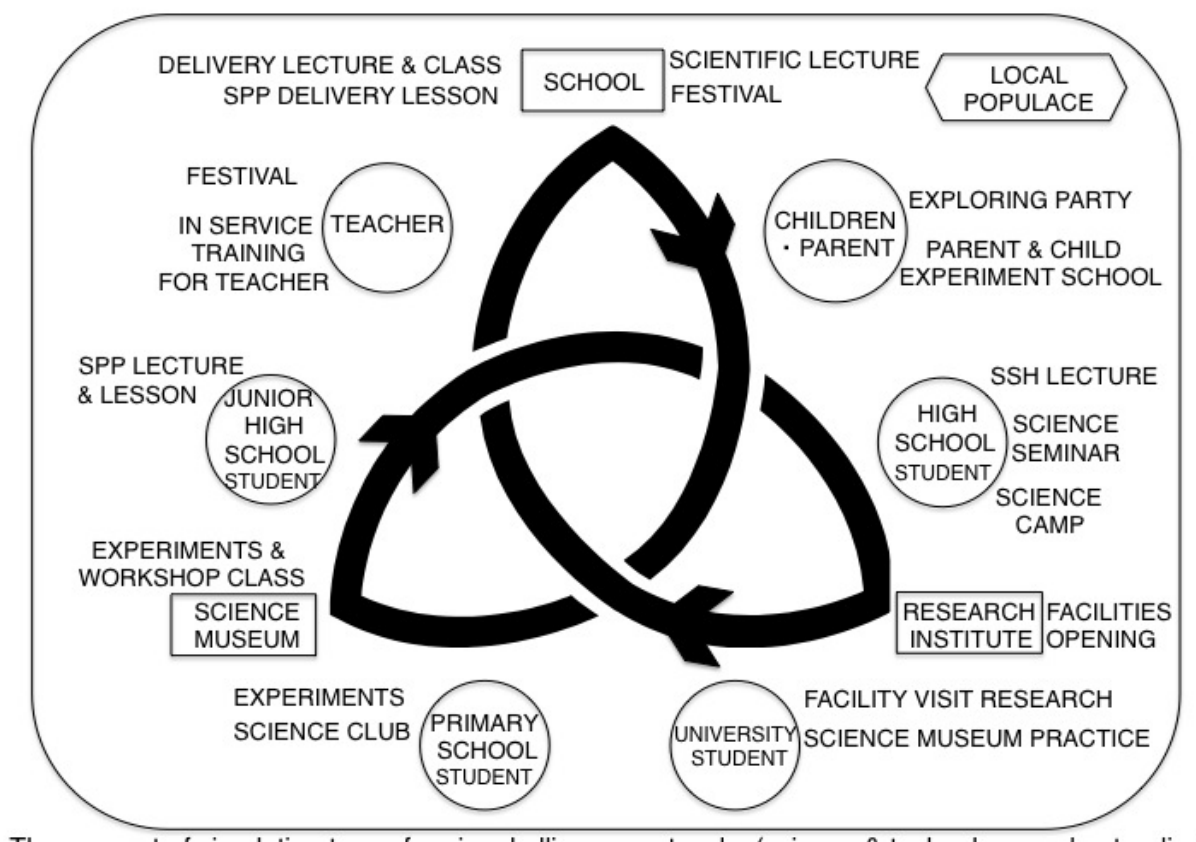

The concept of circulation type of regional alliances networks (science \& technology understanding)

Figure 6. The concept of circulation type of networks in understanding activities on science and technology field 